\title{
"VÃO-SE OS PARTIDOS, MAS FICA A ARENA": A FORMAÇÃO DA ARENA E DO MDB E AS DISPUTAS POLÍTICAS NO ESTADO DO AMAZONAS (1964-1966)
}

\author{
"PARTIES GO, BUT ARENA REMAINS": THE FORMATION OF ARENA AND THE \\ POLITICAL DISPUTES IN THE STATE OF AMAZONAS (1964-1966)
}

César Augusto Bubolz, Queirós*

\begin{abstract}
RESUMO
O presente artigo tem como objetivo compreender o processo de reestruturação político-partidária ocorrido no estado do Amazonas após a instauração do Ato Institucional $n^{\circ} 2$, buscando analisar o processo de formação dos novos partidos e abordar a forma como as disputas politicas existentes no estado, no periodo anterior ao golpe de 1964, foram ressignificadas a partir do AI-2. Nossa ênfase recairá sobre as eleições legislativas de 1966 e sobre as articulações políticas para a consolidação da Aliança Renovadora Nacional (ARENA), no estado.
\end{abstract}

PALAVRAS-CHAVE: Amazonas. Partidos Politicos. Ditadura. ARENA.

\begin{abstract}
This article aims to understand the process of party-political restructuring that took place in the state of Amazonas after the establishment of institutional act $n^{\circ} 2$, seeking to analyze the process of formation of new parties and the way in which the political disputes existing in the state in the period prior to the 1964 coup were resignified from the AI-2. Our emphasis will be on the 1966 legislative elections and on the political articulations for the consolidation of the National Renovating Alliance (ARENA), in the state.
\end{abstract}

KEYWORDS: Amazonas. Political Parties. Ditactorship. ARENA.

Com o golpe de 1964, a democracia brasileira sofreu um violento ataque e, rapidamente, foi posto em prática um processo de instalação de um forte aparato autoritário, alicerçado por um reordenamento do sistema jurídico. A oposição foi violentamente perseguida e eliminada do jogo através das cassações e suspensões de direitos políticos por força de atos institucionais decretados pelo Poder Executivo, investido de funções legislativas. Neste contexto, o Partido Trabalhista Brasileiro (PTB) e seus correligionários foram alvos privilegiados do aparato estatal. No estado do Amazonas, o governador

\footnotetext{
* Professor da Universidade Federal do Amazonas (UFAM). Doutorado em História pela Universidade Federal do Rio Grande do Sul (UFRGS). Email: cesardequeiros@gmail.com.
} 
Plínio Ramos Coelho (PTB) foi deposto e, em seu lugar, assumiu Arthur Cezar Ferreira Reis. Com o decreto do Ato Institucional n 2 (AI-2), de 27 de outubro de 1965, que extinguiu os partidos políticos existentes e estabeleceu eleição via Colégio Eleitoral para a Presidência da República, o país - e o estado do Amazonas - iniciaram um processo de reordenamento do sistema político a partir de bases profundamente autoritárias e da criação de novas legendas (ARENA e MDB). Na prática, foi o início do bipartidarismo no país. Buscaremos analisar de que forma as disputas políticas existentes no estado, no período anterior ao golpe de 1964, foram ressignificadas a partir do AI-2, analisando o processo de formação das novas agremiações políticas no estado do Amazonas visando às eleições de 1966.

\section{O GOLPE DE 1964 E O AI-2}

Em 1964, o Brasil vivenciou um golpe civil-militar que mergulhou o país em um período de 21 anos de repressão, censura, autoritarismo e violações. A fim de institucionalizar a ditadura que se seguiu ao golpe e criar um aparelho jurídico-legal que desse ares de legitimidade ao novo regime, os militares passaram a fazer uso sistemático de medidas legislativas denominadas de atos institucionais que visavam moldar o aparato jurídico e, paralelamente, enfraquecer o poder legislativo. De fato, eram os militares quem, concretamente, legislavam por meio dos atos institucionais e atos complementares, normas arbitrariamente editadas pelos comandantes das forças armadas ou pelo Presidente da República, sem qualquer consulta popular ou participação dos membros do poder legislativo, eleitos como representantes do povo. A despeito da manutenção formal da constituição de 1946, por meio dos atos institucionais os militares, gradativamente, foram dando forma ao novo regime. Segundo o Relatório da Comissão Nacional da Verdade:

A ordem jurídica do regime militar era híbrida: ainda vigorava a Constituição de 1946,
porém, nos limites estabelecidos pelos atos institucionais que passaram a ser editados.
Em outras palavras, ao lado de uma ordem de base constitucional, de caráter
permanente, havia uma ordem de base institucional, de caráter transitório, que
vigoraria o tempo que fosse necessário para consolidar o projeto político dos
militares. As Constituições de 1946 e de 1967 - alterada pela Emenda Constitucional
no $1 / 1969$ - e os atos institucionais editados durante o regime eram tidos pelos
militares como normas fundacionais, a partir das quais se construiu o ordenamento
jurídico da ditadura (CNV, 2014, p. 935).

No preâmbulo do ato institucional que ficou conhecido como Ato Institucional no 1 (AI-1), de 9 de abril de 1964, que introduziu significativas alterações no texto constitucional de 1946, fica evidente a necessidade de "institucionalização" do regime. O Poder Executivo toma para si as tarefas do Legislativo e "se investe no exercício do Poder Constituinte", reivindicando a "capacidade de constituir o novo governo" porque "contém a força normativa, inerente ao Poder Constituinte". Assim, "ela [a dita 'revolução'] edita normas jurídicas sem que nisto seja limitada pela normatividade anterior à sua vitória" (Jornal do Commercio, 22/01/1966). 
Ainda que o Congresso Nacional tenha sido mantido em funcionamento - com a exceção de alguns breves períodos -, tratava-se apenas de manter as aparências, uma vez que foi efetuada uma "operação limpeza"1, excluindo parlamentares de oposição e coagindo os demais a permanecerem em silêncio. Desta forma, a aparente legalidade conferia certa legitimidade ao novo regime e buscava passar a imagem da manutenção do funcionamento das instituições.

Composto de 11 artigos, o AI-1 concedia ao comando revolucionário as prerrogativas de cassar mandatos legislativos, suspender direitos políticos pelo prazo de dez anos e deliberar sobre a demissão, a disponibilidade ou a aposentadoria dos que tivessem "atentado" contra a segurança do país, o regime democrático e a probidade da administração pública. Determinava, ainda, que, dentro de dois dias, seriam realizadas eleições indiretas para a presidência e vice-presidência da República, cujo mandato se estenderia até de janeiro de 1966, data em que expiraria a vigência do próprio ato.

No dia seguinte ao AI-1, foi divulgada a primeira lista de cassações, com 102 nomes. Foram cassados os mandatos de 41 deputados federais e suspensos os direitos políticos de várias personalidades de destaque na vida nacional, entre as quais João Goulart; o ex-presidente Jânio Quadros; o secretáriogeral do proscrito Partido Comunista Brasileiro (PCB), Luís Carlos Prestes; o governador deposto Miguel Arraes, de Pernambuco; o deputado federal e ex-governador do Rio Grande do Sul, Leonel Brizola. No dia 11 de abril de 1964, o Congresso Nacional ratificou a indicação do general Humberto Castelo Branco, chefe do Estado-Maior do Exército e um dos principais articuladores da derrubada do presidente João Goulart. Seu mandato se estenderia até janeiro de 1966, devendo convocar eleições presidenciais diretas em 1965. No entanto, em 17 de julho de 1964, o Congresso Nacional aprovou a prorrogação do mandato de Castelo Branco até o dia 15 de março de 1967, suspendendo as eleições presidenciais previstas para outubro de 1965 e adiando o pleito para 3 de outubro de 1966.

Porém, um ano antes da realização das eleições, em outubro de 1965, a frágil esperança de reestabelecimento do regime democrático mediante a realização de eleições diretas para a escolha do novo presidente se desfez em uma "canetada". ${ }^{2} \mathrm{O}$ AI-2 estabeleceu, entre outras medidas autoritárias, a eleição indireta para a presidência da República e a dissolução de todos os partidos políticos então existentes. Visto como um aprofundamento do autoritarismo e demonstração evidente do intuito de perpetuação dos militares no poder, o AI-2 pode ser entendido como uma reação aos resultados das eleições que ocorreram no início daquele mês e que deram vitória a vários candidatos oposicionistas. Entre as medidas autoritárias estabelecidas por este ato estavam o poder conferido ao presidente da

\footnotetext{
${ }^{1}$ Essa evolução é essencial para bem caracterizar diversos outros episódios do período, pois informa que o projeto repressivo baseado numa "operação limpeza" violenta e longeva estava presente desde os primeiros momentos do golpe. Assim, o Ato Institucional $\mathrm{n}^{\circ} 5$ foi o amadurecimento de um processo que se iniciou muito antes, e não uma decorrência dos episódios de 1968, diferentemente da tese que sustenta a metáfora do "golpe dentro do golpe", segundo a qual o AI-5 iniciou uma fase completamente distinta da anterior. Trata-se de reafirmar a importância, como projeto, do que se pode chamar de "utopia autoritária", isto é, a crença de que seria possível eliminar quaisquer formas de dissenso (comunismo, "subversão", "corrupção") tendo em vista a inserção do Brasil no campo da "democracia ocidental e cristã" (FICO, 2004, p. 33).

2 Para utilizar uma expressão que atualmente circula nos noticiários políticos.
} 
República de alterar a Constituição ${ }^{3}$; a eleição do presidente e do vice-presidente se realizaria através do Congresso Nacional, em sessão pública e votação nominal; a decretação ou prorrogação de estado de sítio pelo prazo máximo de cento e oitenta dias; as garantias constitucionais ou legais de vitaliciedade, inamovibilidade e estabilidade foram suspensas; o presidente poderia suspender os direitos políticos de quaisquer cidadãos pelo prazo de 10 (dez) anos, além de cassar mandatos legislativos federais, estaduais e municipais; a extinção dos partidos políticos existentes, entre outras. Sua implantação foi justificada, em seu preâmbulo, da seguinte forma:

\begin{abstract}
Agitadores de vários matizes e elementos da situação eliminada teimam, entretanto, em se valer do fato de haver ela reduzido a curto tempo o seu período de indispensável restrição a certas garantias constitucionais, e já ameaçam e desafiam a própria ordem revolucionária, precisamente no momento em que esta, atenta aos problemas administrativos, procura colocar o povo na prática e na disciplina do exercício democrático. Democracia supõe liberdade, mas não exclui responsabilidade nem importa em licença para contrariar a própria vocação política da Nação. Não se pode desconstituir a revolução, implantada para restabelecer a paz, promover o bemestar do povo e preservar a honra nacional (BRASIL, 1965).
\end{abstract}

No pleito de outubro de 1965, em 6 dos 11 estados em que ocorreram eleições de governadores foram vitoriosos candidatos que representavam a oposição ao governo: na Guanabara, foi eleito Francisco Negrão de Lima, pela coligação Partido Social Democrático (PSD)/PTB); em Mato Grosso, Pedro Pedrossian, pelo PSD; em Minas Gerais, Israel Pinheiro da Silva, pelo PSD; no Paraná, Paulo Pimentel, pelo Partido Trabalhista Nacional (PTN); no Rio Grande do Norte, Walfredo Gurgel, pelo PSD; e, em Santa Catarina, Ivo Silveira, pela coligação PSD-PTB. Como as eleições para o executivo estadual do Amazonas haviam ocorrido em 1962, o próximo pleito para o governo do estado ocorreria apenas em 1966. A força simbólica da aliança entre PSD-PTB e o apelo eleitoral que tais partidos possuíam pareciam ser um grande obstáculo à redução da representatividade política destas agremiações e à consolidação do projeto golpista em curso. ${ }^{4}$ Os resultados eleitorais de 1965 vieram trazer essa constatação à tona. Com isso, a extinção dos partidos políticos existentes e o reordenamento políticopartidário no país traziam consigo a clara intenção de eliminar o capital eleitoral adquirido por estas siglas e de enfraquecer suas lideranças, como observa Kinzo (1988, p. 27):

A tentativa do regime de trabalhar com os partidos políticos do antigo regime não conseguira assegurar uma base sólida e estável para o governo no Congresso, pois a principal força política de apoio à "revolução" - a UDN - não era suficientemente numerosa para prover sozinha aquela base. Ademais, os problemas que haviam surgido com a candidatura presidencial de Carlos Lacerda, que passou a se opor abertamente a Castelo Branco, tornara indispensável a extinção mesmo daquele partido que havia fornecido o maior respaldo civil ao movimento de 1964.

\footnotetext{
${ }^{3}$ Caso os projetos de lei de iniciativa da Presidência da República não fossem votados em um prazo de até 45 dias, o texto seria considerado aprovado.

${ }^{4}$ A despeito da aliança que ocorria nacionalmente entre PSD e PTB, no estado do Amazonas, os dois partidos se tornaram rivais desde o rompimento político de Plínio Ramos Coelho (PTB) com Álvaro Botelho Maia (PSD), logo após a eleição de Maia para o governo do estado em 1950 (QUEIRÓS, 2016, p. 51).
} 
Na sessão do Senado Federal do dia 28 de outubro de 1965, no dia seguinte à divulgação do AI2, o então senador Arthur Virgílio Filho proferiu forte discurso criticando a brusca mudança política que era imposta e conclamando seus colegas parlamentares a defenderem a democracia: "Ou seremos dignos do mandato popular que recebemos ou estaremos entregando esta nação ao mais degradante dos destinos" (ARTHUR VIRGÍLIO FILHO, 2011, p. 10). De forma corajosa, o senador (que teve seus direitos políticos cassados em 1969), afirmava:

Falo para um Senado sitiado, falo para uma Casa que deveria ser a encarnação maior da representação democrática de um país absolutamente sitiado. Falo para um Senado que existe apenas nominalmente, falo para um Senado que talvez esteja vivendo as suas últimas horas. Mas é preciso que se fale, é preciso que alguma voz de protesto se levante, é preciso que se manifeste inconformismo diante da situação que atravessa nossa desgraçada pátria, nesta hora infeliz, triste e infeliz, em que não sabemos o dia de amanhã, não sabemos se estaremos aqui ou num cárcere, não sabemos se esta Casa estará funcionando ou alguém legislando, impondo, por decreto, sua vontade ao povo (ARTHUR VIRGÍLIO FILHO, 2011, p. 338).

Diante do aprofundamento do golpe e da iminência de perpetuação da ditadura dos militares, de forma muito lúcida, Virgílio Filho parecia antever o que estava por acontecer com o país:

Que será desta nação amanhã? Onde estarão as nossas liberdades? O que será da democracia brasileira? Ninguém sabe, ninguém pode dizer! Talvez este Senado esteja fechado; talvez aqueles homens de imprensa já não possam mais escrever aquilo que pensam e sentem, porque haverá censor em cada jornal; talvez os rádios não falem mais a verdade sobre o país, mas apenas mentira, aquela mentira que segundo Goebbels, se repetida, se tornaria verdade. Talvez sejamos apenas massa amorfa, sem vontade, sem dignidade, sem liberdade, a aceitar um regime que não escolhemos e que não queremos (ARTHUR VIRGÍLIO FILHO, 2011, p. 338).

Neste quadro, a ditadura avançou em seu projeto de perpetuação no poder através da imposição de eleição indireta para presidente da república via Colégio Eleitoral, da eleição indireta para os governos estaduais e do estabelecimento do bipartidarismo. Com a extinção dos partidos políticos existentes, as novas agremiações deveriam se organizar a partir das orientações definidas no ato complementar $\mathrm{n}^{\circ} 4$ (AC-4), que atribuíu aos membros do Congresso Nacional a tarefa de, dentro do prazo de 45 dias, promover a criação de organizações que teriam atribuições de partidos políticos. Tais agremiações não poderiam utilizar "nomes, siglas, legendas e símbolos dos partidos extintos" e era "vedada a designação ou denominação partidária, bem como a solicitação de adeptos, com base em credos religiosos ou em sentimentos regionalistas de classe ou de raça" (BRASIL, AC-4, 1965). De acordo com o Ato Complementar, o processo de reordenamento seria transitório, uma vez que estava destinado às eleições de 1966 e, passadas as eleições, seria promovida a organização dos partidos políticos com base na lei ${ }^{\circ}$ 4.740, de 15 de julho de 1965. As organizações criadas com base naquele ato poderiam solicitar registro como partido político, a partir de 1967. O AC-4 determinava que essas agremiações deveriam contar com o apoio de, no mínimo, 120 deputados federais e 20 senadores, o que inviabilizava a criação de mais de dois ou três partidos, determinava uma verticalização das organizações políticas, criadas de cima para baixo, via Congresso Nacional, e estabelecia, na prática, o bipartidarismo. 
No final de 1965, as tratativas para a criação das novas agremiações já estavam ocorrendo de modo acelerado: por um lado, o Movimento Democrático Brasileiro (MDB) obteve seu registro junto ao Tribunal Superior Eleitoral em março de 1966, encontrando, contudo, dificuldades para completar o número mínimo de parlamentares exigido pela lei para criar sua agremiação (MOTTA, 1996, p. 203). Por outro lado, utilizando-se da estrutura partidária da extinta União Democrática Nacional (UDN), a Aliança Renovadora Nacional (ARENA) também vinha se articulando desde o final de 1965, buscando equilibrar interesse de "grupos heterogêneos e de diferentes tendências políticas, oriundos dos extintos partidos, cujos interesses e rivalidades, sobretudo em nível estadual e local, eram difíceis de conciliar" (BATISTELLA, 2020, p. 194).

Assim, no início de 1966, as novas bases do sistema político brasileiro e do bipartidarismo já estavam formadas, com a criação das duas legendas: ARENA e MDB. Enquanto a ARENA contava nacionalmente com a adesão de 257 deputados federais e 44 senadores, o MDB totalizava 149 deputados federais e 21 senadores. Segundo Motta, "o partido da oposição era formado basicamente por elementos oriundos do PTB e do PSD. Os parlamentares pertencentes a esses dois partidos perfaziam, juntos, cerca de 80\% dos deputados" (MOTTA, 1996, p. 205). De outra parte, os quadros da ARENA eram compostos basicamente por parlamentares oriundos da UDN e do PSD: 89,6\% dos deputados udenistas e $64,5 \%$ da bancada pessedista ingressaram na ARENA. No entanto, Batistella salienta que " $14,8 \%$ da bancada arenista era constituída por ex-petebistas, uma vez que 32,7\% (quase um terço) dos deputados do PTB (os "bigorrilhos" ou adesistas) optaram por filiar-se ao partido do governo" (BATISTELLA, 2020, p. 194).

\section{O GOLPE DE 1964: AUTORITARISMO, ELEIÇÕES E DISPUTAS POLÍTICAS}

No estado do Amazonas, o golpe trouxe rápidas consequências e logo a repressão se abateu sobre o meio político. Na ocasião da deflagração do golpe civil-militar que destituiu o presidente João Melchior Goulart, o Amazonas era governado por Plínio Ramos Coelho, que enfileirava o terceiro mandato consecutivo do PTB no governo do estado. De imediato, se estabeleceu uma profunda desconfiança de que, com a chegada dos militares ao poder, o governador eleito em 1962 permaneceria muito pouco tempo no cargo (QUEIRÓS, 2019b, p. 544). Tal desconfiança era legítima e se fundamentava tanto em questões referentes ao clima político vivenciado no país quanto em questões ligadas às disputas políticas estaduais. Na primeira lista dos 102 nomes que tiveram seus direitos políticos cassados após o AI-1, divulgada em 10 de abril de 1964, já constavam os nomes de Gilberto Mestrinho, ex-governador do Amazonas (1958-1962) e eleito deputado federal por Roraima, e do deputado federal Almino Monteiro Alvares Afonso, eleito pelo PTB em 1962. Almino Afonso havia sido o candidato mais votado para a Câmara dos Deputados pelo Amazonas, reelegendo-se com 13.870 votos e exercendo a função de líder do PTB na Câmara. Foi Ministro do Trabalho e da Previdência Social de João Goulart (QUEIRÓS, 2019a, p. 39). 
No mês seguinte, foi a vez do deputado Arlindo Porto (PTB) ter seu mandato cassado, após reunião ordinária da Assembleia Legislativa do Estado do Amazonas (ALEAM), tendo sido preso logo em seguida. Arlindo Porto foi o primeiro deputado estadual a perder o mandato durante a ditadura militar. Em Manaus, o vereador Manoel Rodrigues da Silva, ex-dirigente do Sindicato dos Estivadores, e seu suplente Othon Mendes, além do vereador Nathanael Rodrigues, todos eleitos pelo PTB, também tiveram seus mandatos cassados na Câmara de Vereadores de Manaus (QUEIRÓS, 2019a, p. 40). Os sindicatos, como o Sindicato dos Estivadores, sofreram forte intervenção militar, com a perseguição, prisão e afastamento de dirigentes e nomeação de interventores para seus postos (Jornal do Commercio, 28/04/1964).

Com o golpe de 1964 e a deposição do presidente João Goulart, a situação do governador Plínio Coelho tornou-se bastante delicada e os dias que se seguiram foram de profunda agitação e instabilidade. As notícias e especulações sobre a iminente deposição do governador eram constantes. Finalmente, em 14 de junho, quando o governador Plínio Coelho discursava durante a cerimônia de abertura do VIII Festival Folclórico do Amazonas, no estádio General Osório, foi surpreendido pela informação de sua deposição, trazida pelo general Jurandir Mamede. O governador Plínio Coelho teve seu mandato cassado, seus direitos políticos suspensos por dez anos e, meses depois, por ordem do próprio governador Arthur Cezar Ferreira Reis, teve sua prisão decretada em virtude de alegadas denúncias de corrupção, associadas à constituição de uma sociedade anônima com o nome de Paranauari, denúncias essas apresentadas pelos deputados da oposição parlamentar ao seu governo.

A censura e a repressão logo se estabeleceram no estado do Amazonas: os jornais O Trabalhista e $A$ Gazeta, ambos pertencentes ao grupo Difusão, foram fechados por ordem do governador Arthur Cezar Ferreira Reis e seus redatores foram enquadrados na Lei de Segurança Nacional. Seu redatorchefe, Manoel José Antunes, foi preso e recolhido ao quartel da milícia, incurso na Lei de Segurança Nacional (Jornal do Commercio, 13/08/1964). Neste episódio, o senador Desiré Guarani considerou que o fechamento dos periódicos teria sido motivado pela publicação de um ofício do Tribunal de Contas da União indicando nomes de pessoas que teriam deixado de prestar contas de verbas recebidas da Superintendência do Plano de Valorização Econômica da Amazônia (SPVEA) quando Arthur Reis era superintendente daquele órgão, o que caracterizaria uma pequena vingança pessoal (QUEIRÓS, 2019b, p. 558). Tal atitude levou a Associação Amazonense de Imprensa (AAI), sob a presidência de Aristophano Anthony, a redigir um ofício endereçado ao governador apelando para que os dois jornais, que se encontravam ocupados pelas forças da Polícia Militar, fossem autorizados a voltar a circular normalmente. O presidente da AAI recebeu do senador Arthur Virgílio um ofício no qual este prestava sua solidariedade a "todos os jornalistas amazonenses atingidos pela medida arbitrária do governador Arthur Reis" (Jornal do Commercio, 13/08/1964).

Os conflitos do novo governador com os outros poderes do estado - Legislativo e Judiciário também foram bastante intensos. No mesmo dia da prisão do ex-governador Plínio Coelho, Arthur Cezar Ferreira Reis ordenou a ocupação militar do parlamento estadual - que funcionava 
provisoriamente no Instituto de Educação do Amazonas (IEA) - com a justificativa de evitar "o aumento inconstitucional e imoral votado por deputados, dos seus próprios subsídios", acusando-os de terem agido dessa forma em função da necessidade de compensar perdas de recursos econômicos provocadas pela supressão de alguns municípios no estado. O governador havia decretado uma medida que extinguia mais de 200 municípios criados durante o governo de Plínio Coelho, no interior do Amazonas. Tal medida descontentou muitos parlamentares, principalmente aqueles que possuíam bases eleitorais sólidas nessas cidades. Como represália, no mesmo dia, a Assembleia Legislativa aprovou, em regime de urgência, um projeto que aumentava os subsídios dos parlamentares e do governador. Arthur Reis vetou o projeto. No entanto, seu veto foi derrubado na Assembleia Legislativa por 18 votos a 8. Neste momento de disputa entre os dois poderes, o Executivo se impôs pela força, com a ocupação do legislativo estadual (QUEIRÓS, 2019b, p. 557). Para contornar a crise entre Executivo e Legislativo, foi necessária a vinda a Manaus do comandante da $8^{a}$ Região Militar e do Comando Militar da Amazônia (CMA), Jurandir Mamede, que se reuniu com diversas lideranças, entre elas o presidente da Assembleia. Entre os desdobramentos da crise entre os dois poderes, devemos salientar a exoneração do Secretário de Educação José Bernardino Lindoso e a saída do PSD da base governista (no estado).

Os conflitos com o Judiciário também assumiram uma proporção bastante significativa. Após a prisão do governador deposto por ordem de Arthur Cezar Ferreira Reis, o Judiciário estadual resolveu acatar um pedido de habeas corpus impetrado pelo advogado de Plínio Ramos Coelho. No dia da votação, o Palácio de Justiça do Amazonas amanheceu cercado por soldados da Polícia Militar, em uma clara tentativa de intimidação e coerção do Judiciário. Apesar disso, a decisão em favor da concessão do Habeas Corpus foi unânime, tendo sido expedido alvará de soltura em favor do ex-governador. Os juízes deliberaram que,

[...] em face da informação dirigida pelo Sr. governador, não se tem definição dos crimes que seriam de responsabilidade do paciente e, de outro lado, frente aos dispositivos legais correlativos, o Governador não é autoridade competente para ordenar a prisão de quem quer que seja (GARCIA, 2002, p. 54).

No entanto, por ordem do governador Arthur Reis, o alvará de soltura não foi cumprido. Diante disso, o Tribunal de Justiça do Amazonas enviou um ofício a Arthur Reis estabelecendo o prazo de uma hora para a libertação de Plínio. Em resposta, o governador afirmou que, por ordem das autoridades militares federais, Plínio Coelho foi transferido da Penitenciária Estadual para o $27^{\circ}$ Batalhão de Caçadores, no bairro São Jorge. Nesta ocasião, as disputas entre o Executivo e o Judiciário já estavam muito acirradas, ao ponto de, em sinal de protesto público frente às constantes ameaças transmitidas ao Judiciário por membros do Poder Executivo, os desembargadores Leôncio de Salignac e Souza, Benjamim Magalhães Brandão, Roosevelt Pereira de Melo, Oyama Cézar Ituassú da Silva e Sebastião Salignac de Souza terem requerido suas aposentadorias, em caráter irrevogável (QUEIRÓS, 2019b, p. 557). No dia 12 de agosto, para enorme descontentamento do governador, Plínio Ramos Coelho foi posto em liberdade. Sentindo-se desmoralizado pela soltura de Plínio, Arthur Reis redigiu de próprio 
punho sua renúncia ao cargo, entregando-a pessoalmente ao presidente da Assembleia Legislativa, deputado Rui Araújo. Para dissuadir o governador, que só permaneceria no cargo se Plínio Coelho fosse preso, o General Castelo Branco autorizou sua prisão pelo crime de corrupção, ordenando que ele fosse detido "onde estivesse" (Estado de São Paulo, 16/08/1964).

Neste quadro, restou à Assembleia Legislativa recusar o pedido de renúncia de Arthur Cezar Ferreira Reis, que permaneceu no governo fortalecido pelo apoio do presidente Castelo Branco e tendo vencido a queda de braço tanto com o Poder Legislativo quanto com o Judiciário (Jornal do Commercio, 21/08/1964). O Legislativo subjugado e o Judiciário sob ameaça tiveram que se curvar - não sem resistências e protestos - às decisões do governador (QUEIRÓS, 2019, p. 558). Um edital publicado no Jornal do Commercio, do Rio de Janeiro, comemora que "a Revolução chegara à Amazônia. E revigorada. Acicatada. Para valer. A crise ontem encerrada com a recusa, pela Assembleia Legislativa, da renúncia do governador Arthur Cesar Ferreira Reis, significa a outorga de todo o poder aos revolucionários" (Jornal do Commercio, 21/08/1964).

A deposição do governador Plínio Ramos Coelho no estado do Amazonas encerrou um período de hegemonia trabalhista iniciado com sua eleição, em 1954, com a eleição de seu sucessor, Gilberto Mestrinho, em 1958, e com a recondução de seu nome para um segundo mandato, em 1962. No entanto, o processo de consolidação da hegemonia do PTB no Amazonas a partir da eleição de Plinio Ramos Coelho, em 1954, propiciou o crescimento de um conjunto de rivalidades com os herdeiros do alvarismo, derrotado naquelas eleições e cujo espaço político foi significativamente reduzido nas eleições seguintes. A consolidação do PTB no estado do Amazonas pode ser verificada pelos resultados eleitorais: embora as eleições de 1962 tenham sido muito disputadas, uma vez que os aliados do alvarismo se empenharam em retomar o poder no estado lançando a candidatura de Paulo Nery, do Partido Social Progressista (PSP), em aliança com a UDN e o PSD, o PTB não apenas venceu o pleito majoritário, com a eleição de Plínio Ramos Coelho para o terceiro mandato do partido (fazendo 54.800 votos, contra 42.878 de Paulo Pinto Nery), como conseguiu eleger dois senadores (Antovila Mourão Vieira e Arthur Virgilio Filho). Álvaro Maia havia sido, novamente, derrotado em uma eleição, o que confirma a queda gigantesca em seu prestígio e o declínio do alvarismo. Dos sete deputados federais eleitos, o PTB elegeu três, além de outros seis deputados estaduais (QUEIRÓS, 2020, p. 22).

Com o golpe de 1964, parecia ser a hora do ajuste de contas. Tal impressão pode ser facilmente verificada nos jornais que, após o golpe, criticavam as gestões do PTB, acusando os trabalhistas de terem mergulhado o estado em uma profunda "decomposição moral" e afirmando que o Amazonas era "a maior vítima da hecatombe trabalhista que espoliou esse país", visto que "ali se instalou a mais terrível máquina de corrupção laborista que desde o início do fabianismo se conhece" (Jornal do Commercio, 21/08/1964). Com a deposição do governador Plínio Ramos Coelho, era o momento da retomada do poder político pelos grupos que vinham sendo derrotados desde 1954. O AI-2 - juntamente com o Ato complementar $\mathrm{n}^{\circ} 4$ - representava a possibilidade de um reordenamento político que poderia recolocar no poder as forças políticas ligadas a Álvaro Maia e à UDN, mas de forma ressignificada, a partir de 
outras legendas e sob a bandeira da "Revolução Vitoriosa". O trabalhismo foi esvaziado não apenas pela extinção do PTB - bem como de todos os partidos políticos existentes - mas pela sua associação à corrupção e à subversão.

\section{ARENA E MDB: O NOVO ORDENAMENTO POLÍTICO NO ESTADO DO AMAZONAS}

No ano de 1965, os grupos e partidos políticos do estado já se preparavam para a disputa pela cadeira de chefe do Executivo amazonense, que ocorreria no ano seguinte (1966). As articulações dos partidos políticos - que se reorganizavam e buscavam espaços de atuação após o golpe de 1964 - já estavam ocorrendo de forma acelerada. No entanto, a extinção dos partidos políticos estabelecida pelo ato de 27 de outubro daquele ano parece ter surpreendido a todos e obrigou as lideranças políticas locais a buscar uma rápida adaptação àquela nova realidade.

No início do ano seguinte, novas medidas autoritárias foram implementadas, com o estabelecimento do Ato Institucional no 3 , de 5 de fevereiro de 1966. Este novo ato estendeu o processo de eleição indireta - definido pelo AI-2 para a presidência e vice-presidência da República - para os governos dos estados e estabelecia que os prefeitos das capitais seriam nomeados pelos governadores, e estabeleceu os prazos para a realização dos pleitos: as eleições para governadores e vice-governadores ocorreriam em 3 de setembro; para presidente e vice-presidente da República, em 3 de outubro; e para senadores e deputados federais e estaduais, em 15 de novembro. Deste modo, as eleições para o governo do estado não passariam mais pela consulta à população e seriam responsabilidade da Assembleia Legislativa, em sessão pública e votação nominal. O voto dos parlamentares seria nominal e ostensivo, sendo possível identificar os votantes, o que evidenciava o caráter coercitivo do novo processo eleitoral e demonstrava que o governo federal não estava disposto a se arriscar em eleições livres e diretas.

Neste contexto, o processo de formação dos novos partidos políticos já ocorria de forma acelerada e, no estado do Amazonas, o próprio governador Arthur Cezar Ferreira Reis tomou para si a responsabilidade de constituir o diretório estadual da Aliança Renovadora Nacional. Com a atuação do governador, a ARENA constituiu-se tendo "sólida base parlamentar, tanto nas duas casas do Congresso Nacional como, expressivamente, na Assembleia Legislativa" (Jornal do Commercio, 22/01/1966).

Para dirigir o partido, foi escolhido o deputado Rui Araújo que, segundo o Jornal do Commercio, seria "pessoa da amizade pessoal do governador Arthur Reis" e que, além disso, era "homem de inegável estatura moral e política" (Jornal do Commercio, 22/01/1966). Rui Araújo pertencia ao PSD, foi eleito deputado federal em 1950 e, nas eleições de 1954, foi derrotado nas urnas por Plínio Ramos Coelho, eleito para o seu primeiro mandato. Com a escolha de Rui Araújo para presidir a ARENA, o processo de formação do novo partido - que tomaria o lugar dos "antigos e obsoletos partidos extintos - ficaria a cargo de um "timoneiro seguro" (Jornal do Commercio, 22/01/1966).

Concomitantemente, iniciavam as articulações para a criação do diretório do MDB amazonense. No final do mês de janeiro, ocorreu uma reunião na casa de Elson do Carmo Ribeiro (irmão de Arthur 
Virgílio), que contou com a participação do deputado Federal João Veiga e dos senadores Edmundo Levy e Arthur Virgílio Filho. ${ }^{5}$ Nesta reunião, ficou acordado que o senador Edmundo Levy assumiria a presidência da nova legenda. Além dos nomes já mencionados, integravam a comissão diretora regional do MDB: Djalma Passos, Paulo Coelho, Manuel Barbuda, os deputados estaduais Joel Ferreira da Silva, João Valério, Francisco de Queiroz, Alfredo Campos e Bernardo Cabral, os vereadores Nathanael Rodrigues e Raimundo Aleixo, além de Albérico Antunes de Oliveira e do suplente de deputado estadual, Mário Almeida (Jornal do Commercio, 26/01/1966). ${ }^{6}$

Uma coluna denominada Contraponto, publicada no Jornal do Commercio, faz uma sátira às novas palavras inseridas em nosso vocabulário desde a "Revolução". Entre as novas palavras - ou novas acepções atribuídas a elas - as duas novas siglas partidárias ganharam novos significados: a ARENA significaria "coletivo para designar o receio de várias pessoas. Exemplo: vão-se os anéis, mas ficam os dedos - vão-se os partidos, mas fica a ARENA" e o MDB, "coletivo que serve para exprimir um grupo de sujeitos que já sabem que vão entrar pelo cano; então passam a apressar a coisa" (Jornal do Commercio, 10/04/1966). As duas novas organizações mal haviam sido criadas e o sentido de sua criação já estava claro: a ARENA estava associada ao receio, ao medo de se opor ao regime e à acomodação/resignação diante do avanço irrefreável do autoritarismo, enquanto o MDB parecia estar destinado a "entrar pelo cano" e quem estava associado a ele possivelmente estaria ciente das consequências.

Já visando à sucessão de Arthur Cezar Ferreira Reis, o deputado estadual Júlio Belém, em uma reunião da Assembleia Legislativa, no mês de março, indicou o nome do deputado e presidente da ALEAM, Rui Araújo, a candidato da ARENA (Jornal do Commercio, 19/03/1966). No entanto, a escolha do candidato à sucessão de Arthur Cezar Ferreira Reis no Amazonas recaiu sobre Danilo Matos Duarte Areosa, presidente da Federação do Comércio do Amazonas e secretário da Fazenda de Arthur Reis. Rui Araújo, presidente do Diretório Estadual da ARENA, foi indicado para o cargo de vice-governador (Jornal do Commercio, 17/05/1966)..$^{7}$ O próprio Arthur Reis fez a indicação do nome de seu sucessor e sua decisão foi bastante festejada pelo Jornal do Commercio, que considerava a escolha de Danilo Areosa uma "decisão feliz" de Arthur Reis, uma vez que o candidato à sua sucessão seria "um homem digno em todos os aspectos, jovem cheio de ardor e entusiasmo ${ }^{8}$, que conhece a fundo nossos problemas e vota ao Amazonas muito afeto e muito carinho, estando em perfeitamente condições invejáveis para fazer um bom e fecundo governo" (Jornal do Commercio, 03/06/1966).

De acordo com o que ficou estabelecido pelo Ato Institucional no 3, em setembro de 1966, realizou-se, por meio da Assembleia Legislativa, a eleição indireta para o governo do Amazonas. Foram eleitos Danilo Duarte de Matos Areosa e Rui Araújo. No Amazonas, como em muitos estados, o MDB

\footnotetext{
${ }^{5}$ Arthur Virgílio do Carmo Ribeiro Filho, Edmundo Fernandes Levy e João Veiga pertenciam ao PTB.

${ }^{6}$ Destes, Djalma Passos, Paulo Coelho, João Valério, Mário Almeida e Francisco de Queiroz pertenciam ao Partido Libertador (PL), Manuel Barbuda, Albérico Antunes de Oliveira, Nathanael Rodrigues e Bernardo Cabral eram do PTB, Joel Ferreira da Silva pertencia ao PSB e Alfredo Campos pertencia ao Partido Social Trabalhista (PST) (Jornal do Commercio, 10/02/1966).

${ }^{7}$ No dia 23 de maio de 1966, o governador Arthur Reis enviou mensagem à ALEAM criando o cargo de vice-governador do estado (Jornal do Commercio, 24/05/1966).

8 Areosa completaria 45 anos em 24 de julho.
} 
absteve-se de participar da eleição, não registrando candidatos e nem sequer comparecendo à votação, como foi o caso da eleição de Roberto de Abreu Sodré, em São Paulo (Estado de São Paulo, 04/09/1966).

Nas eleições legislativas de 1966, a primeira após a extinção dos partidos políticos e o reordenamento partidário, a ARENA obteve uma significativa vitória eleitoral no estado, elegendo o senador Álvaro Botelho Maia, cinco deputados federais (Abrahão Sabbá, José Bernardino Lindoso, José Raimundo Esteves, Leopoldo Peres Sobrinho e Raimundo Gomes de Araújo Parente) e vinte e um deputados estaduais, enquanto o MDB elegeu apenas dois deputados federais (Joel Ferreira da Silva e José Bernardo Cabral) e oito estaduais. ${ }^{9}$ Ao analisar a lista de candidatos à eleição de 1966 e comparar os nomes dos candidatos com a lista eleitoral de 1962, é possível perceber de que forma ocorreu a composição dos dois novos partidos. ${ }^{10}$ Dos sessenta e um (61) candidatos que concorreram aos cargos de senador, deputado federal e deputado estadual pela ARENA cujos nomes estavam na referida listagem, dezoito concorreram a cargos eletivos pelo PSD em 1962, seis eram egressos da UDN, seis do PTB, seis do Partido Democrata Cristão (PDC) e os demais pertenciam a partidos como PST, PL, PSB e Partido Republicano Trabalhista (PRT). Não foi possível averiguar a origem partidária de doze nomes. Assim, dos 49 candidatos cuja filiação anterior foi possível de ser apurada pela listagem de 1962, chegamos ao seguinte gráfico:

Gráfico 1 - Filiação partidária anterior dos candidatos a cargos eletivos pela ARENA em 1966

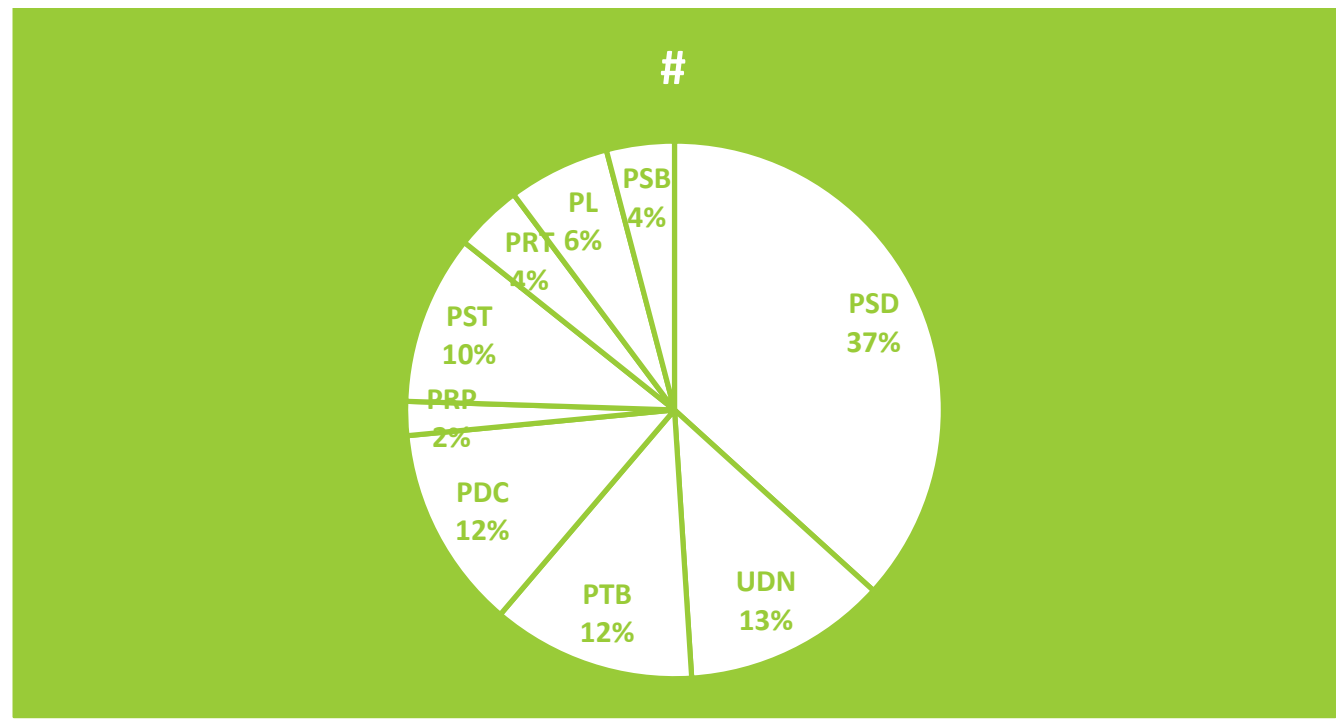

Fonte: Gráfico produzido pelo autor a partir do cruzamento dos dados eleitorais referentes ao estado do Amazonas nos anos de 1962 e 1966.

\footnotetext{
9 Os deputados estaduais eleitos pela ARENA em 1966 foram Álvaro Maranhão, Anfremon D'amazonas Monteiro, Augusto Pessoa Montenegro, Danilo de Aguiar Corrêa, Darcy Augusto Michiles, Francisco Dorval Vieira, Homero Miranda Leão, João dos Santos Braga Júnior, José Austregésilo Mendes, José Belo Ferreira, José Cidade de Oliveira, Júlio Furtado Belém, Osvaldo Tennyson Chaves Monteiro, Rafael Faraco, Rossini Barbosa Lima, Sergio Pessoa Neto, Theomario Pinto da Costa, Tupinambá de Paula e Souza, Vinicius Monteconrado Gomes e Wilson Paula de Sá. O MDB elegeu Alfredo Augusto Pereira Campos, Francisco Guedes de Queiroz, Ismael Benigno, João Bosco Ramos de Lima, João Valério de Oliveira, Léa Alencar Antony, Manuel José de Andrade Neto, Mario Silva D'Almeida, Renato de Souza Pinto, Joel Ferreira da Silva e José Bernardo Cabral

${ }^{10}$ Agradeço ao meu orientando de iniciação científica Raylin Santiago Beckman, que me ajudou no tabulamento dos dados eleitorais.
} 
Os dois principais partidos de oposição ao trabalhismo do estado do Amazonas - PSD e UDN - foram os responsáveis por 50\% do total de filiados na ARENA. Nas eleições de 1962, estes partidos apoiaram Paulo Pinto Nery para o governo do estado e Álvaro Maia para o Senado. Da coligação que apoiou a eleição de Plínio Ramos Coelho em 1962 - PTB, PDC, PL e PST -, temos o significativo percentual de 40\%. É interessante perceber que 12\% dos candidatos que concorreram pela ARENA em 1966 eram oriundos diretamente dos quadros do PTB, sendo marcante a presença de trabalhistas históricos do estado concorrendo a cargos eletivos pela ARENA, como é o caso de Vivaldo Palma Lima Filho. Filho de Vivaldo Lima, Vivaldo Lima Filho foi deputado federal e senador pelo PTB, chegando a assumir a posição de líder do partido no Senado. A filiação de um significativo número de lideranças políticas egressas do PTB na ARENA pode ser melhor compreendida se levarmos em consideração o clima de insegurança, instabilidade e perseguição que as principais lideranças trabalhistas passaram a sofrer desde o golpe de 1964. As cassações, perseguições e o evidente revanchismo político tornavam a opção pela via da filiação no partido que pretensamente seria de oposição um tanto quanto insegura, fazendo com que a tomada de posição pela ARENA poderia garantir maior estabilidade, além de alguma sensação de segurança e/ou ganho pessoal. Grinberg (2009, p. 129) destaca que muitos "não se consideravam oposicionistas e não pretendiam filiar-se ao MDB”.

Se fizermos o mesmo exercício para compreender o processo de formação do MDB no estado, perceberemos que, dos cinquenta e sete (57) candidatos a cargos eletivos que aparecem na listagem eleitoral de 1966, apenas vinte e quatro concorreram nas eleições de 1962. Destes, foi possível chegar ao seguinte gráfico:

Gráfico 2 - Filiação partidária anterior dos candidatos a cargos eletivos pelo MDB em 1966

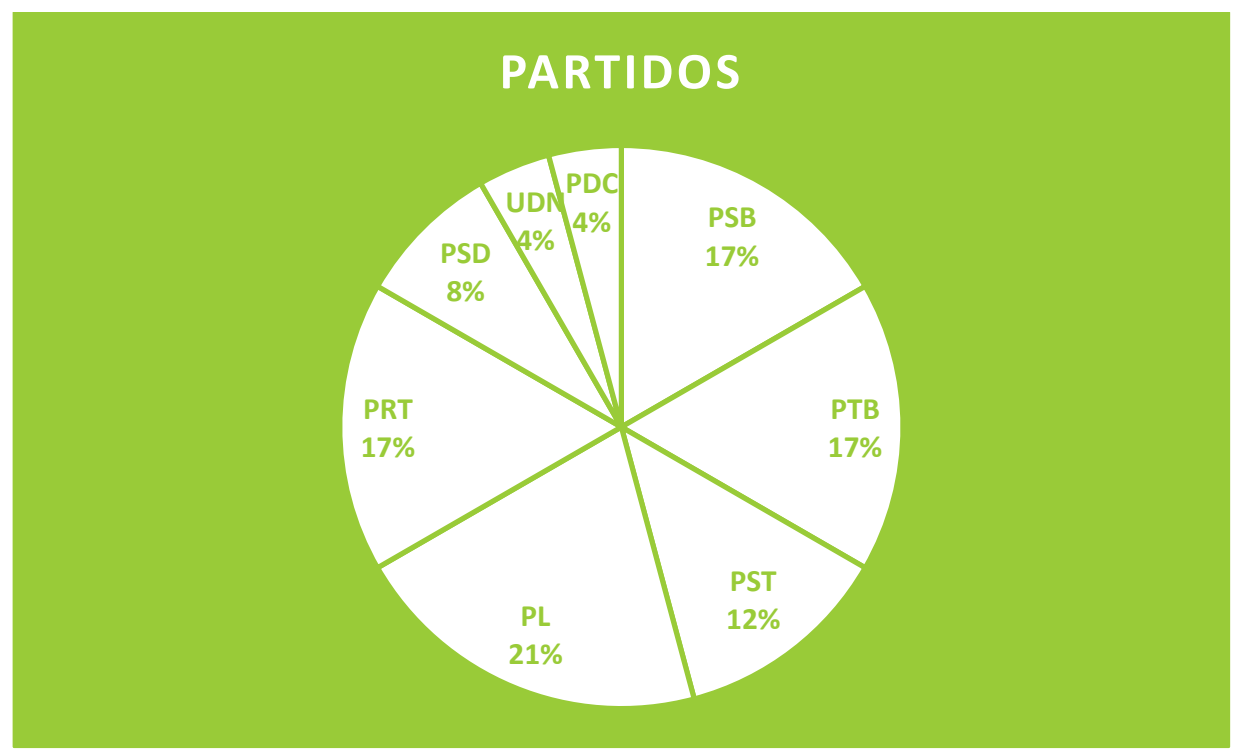

Fonte: Gráfico produzido pelo autor a partir do cruzamento dos dados eleitorais referentes ao estado do Amazonas nos anos de 1962 e 1966. 
Pelo gráfico, é possível perceber que 54\% dos candidatos que concorreram a algum cargo eletivo pelo MDB nas eleições de 1966 pertenceram aos partidos que integraram a coligação que apoiou a eleição de Plínio Ramos Coelho em 1962 - PTB, PDC, PL e PST -, enquanto apenas 12\% pertenciam aos tradicionais partidos de oposição ao trabalhismo do estado (dois eram egressos do PSD e um da UDN). Ao contrário do que ocorreu nacionalmente, onde PTB e do PSD perfaziam, juntos, cerca de $80 \%$ dos deputados federais do MDB e onde o PSD teve um peso significativo (ao lado do PTB) (MOT'TA, 1996, p. 205), no estado do Amazonas, em virtude de uma trajetória política que havia colocado PTB e PSD em campos distintos, a participação de elementos oriundos do PSD na formação do MDB foi muito pouco significativa. Segundo Sobreira (2016, p. 39), “a ARENA durante a ditadura sempre fora associada à UDN, e o MDB ao Partido Social Democrático (PSD)". No entanto, no Amazonas, UDN e PSD constituíram sólida aliança política em virtude das disputas entre o trabalhismo amazonense - que tinha na figura de Plínio Ramos Coelho o seu principal representante - e o alvarismo, uma vez que Álvaro Maia (PSD) - que pode ser considerado a principal liderança política amazonense entre 1930 e, pelo menos, 1954, tendo governado o estado entre 1935 e 1937 e, novamente, entre 1950 e 1954 - sofrera pesado revés eleitoral em 1954. Assim, com a extinção dos partidos políticos, a filiação à ARENA parecia ser um caminho natural para os membros do PSD. Nesta direção, Alessandra Carvalho destaca que, "em alguns casos, a adesão a uma ou outra legenda foi decidida menos com referência à posição diante do regime autoritário, e mais em razão de disputas regionais com grupos políticos adversários" (CARVALHO, 2008, p. 45). Ao que parece, tal afirmação se adequa perfeitamente à realidade do processo político em curso no Amazonas.

Outra constatação interessante que podemos fazer a partir desta análise é que, enquanto mais de $80 \%$ dos candidatos que concorreram a algum cargo eletivo pela ARENA em 1966 haviam disputado as eleições de 1962, apenas 42\% do MDB tinham concorrido na eleição anterior. Este dado nos aponta para o indício de que, no Amazonas, a formação do MDB contou com a forte presença de quadros políticos novos, enquanto a maior parte dos políticos com uma trajetória eleitoral mais longa acabou optando pela segurança da ARENA. Dos onze candidatos que concorreram a cargos eletivos pelo PTB em 1962 e que participaram das eleições de 1966, sete ingressaram na ARENA e quatro no MDB. ${ }^{11}$ Como destaca Motta (1996, p. 205), “um número muito expressivo de líderes políticos de extração popular haviam sido cassados nos primeiros expurgos, desfalcando-se seriamente o campo oposicionista qualitativa e quantitativamente". A perseguição política e a forte coerção exercidas sobre as principais lideranças trabalhistas podem auxiliar a explicar os motivos que levaram parcela significativa dos quadros do PTB amazonense a ingressar na ARENA: poderia ser bastante perigoso alguém com o estigma de ter pertencido ao P'TB optar abertamente por aderir à oposição ao governo.

\footnotetext{
${ }^{11}$ Ingressaram na ARENA Vivaldo Palma Lima Fo José Raimundo Esteves, Augusto Pessoa Montenegro, Darcy Augusto Michiles, Sergio Pessoa Neto, Wilson De Medeiros Calmon, Edmundo Seffair e no MDB José Bernardo Cabral, Renato De Souza Pinto, João De Brito Albuquerque Veiga Filho e Manuel José Machado Barbuda.
} 


\section{CONSIDERAÇÕES FINAIS}

No estado do Amazonas, o golpe de 1964 e as bruscas alterações autoritárias no aparato jurídico brasileiro e nos processos político-eleitorais tiveram como consequência um afastamento temporário ${ }^{12} \mathrm{e}$ uma perda de espaços no campo político do grupo oriundo das fileiras trabalhistas e seu relativo enfraquecimento. Do mesmo modo, essas mudanças permitiram que tais espaços voltassem a ser ocupados por Álvaro Maia e pelos herdeiros do alvarismo - mesmo que de forma subordinada. Embora não mantivesse a influência de anos atrás - uma vez que Arthur Cezar Ferreira Reis passou a exercer forte controle sobre a organização da ARENA, representando os interesses da ditadura no estado -, Maia voltou a exercer importante influência nos rumos da política amazonense, tornando-se um dos representantes do Diretório Estadual da ARENA na convenção que definiu os candidatos nos estados. Arthur Cezar Ferreira Reis e a ditadura militar reconduziram Álvaro Maia e o alvarismo a um papel de centralidade na política amazonense. É evidente, no entanto, que, neste novo cenário, a utilização da estrutura alvarista e de seus quadros pela ditadura militar implicou, necessariamente, uma ressignificação e reelaboração de seus conteúdos políticos e a condução deste processo não estaria mais nas mãos de Maia: Arthur Reis conduziria os rumos políticos do estado com mãos de ferro. Com a eleição de 1966, após sucessivas derrotas eleitorais em suas tentativas de retornar ao Senado (1954, 1958 e 1962), Álvaro Maia finalmente conquistou uma vaga no Senado Federal, tendo falecido em 1969, no curso do mandato. Com a criação da ARENA no estado, foi escolhido para presidente do Diretório Estadual do partido Rui Araújo, velho aliado de Álvaro Maia e representante do alvarismo. Com o golpe, Rui Araújo, que havia sido secretário-geral de Álvaro Maia no período do Estado Novo e tornara-se seu importante aliado, passou a exercer uma posição chave na política estadual, tendo sido eleito presidente da Assembleia Legislativa e escolhido presidente do Diretório Estadual da ARENA. Diante deste papel de destaque após o golpe, Rui Araújo foi eleito vice-governador em 1966, falecendo em 1969, no curso do mandato - após ter sido derrotado nas disputas pelo posto de chefe do Executivo amazonense, nas eleições de 1947 e 1954 e quando disputou uma cadeira na Câmara dos Deputados, em 1958. Com a ditadura e com o ato que estabelecia que os prefeitos das capitais passariam a ser indicados pelos governadores dos estados, Paulo Pinto Neri, candidato apoiado por Álvaro Maia nas eleições para o Executivo estadual de 1958 e 1962, foi indicado por Arthur Reis para chefiar a Prefeitura de Manaus em 1965, tendo sido mantido no cargo pelo sucessor de Reis, Danilo Areosa, até o ano de 1972, quando foi substituído por Frank Abrahim Lima. Em 1978, Neri foi eleito pela Assembleia Legislativa vicegovernador do estado do Amazonas, ao lado do governador José Lindoso, tendo assumido o cargo de governador após a desincompatibilização de Lindoso a fim de concorrer a uma vaga no Senado Federal

12 Podemos interpretar que este "afastamento temporário" se encerra com as eleições de 1982, quando Gilberto Mestrinho, ex-governador do estado pelo PTB, sai vitorioso nas urnas. A partir daí, verificamos a perpetuação de herdeiros políticos dessas lideranças no poder no estado. Desde o retorno das eleições governamentais, em 1982, o Amazonas tem sido governado por um grupo pequeno e relativamente fechado de políticos que ora se aliam, ora se opõem, tendo como patriarca o ex-governador Gilberto Mestrinho. Entre 1983 e 2010, o estado do Amazonas elegeu apenas três governadores, que se alternaram no poder: Gilberto Mestrinho, Amazonino Mendes e Eduardo Braga. 
nas eleições de 1982. Lindoso foi derrotado na disputa e a cadeira do Senado foi conquistada por Fábio Lucena (AMARAL, 2019). A implantação do bipartidarismo e a criação das novas agremiações no estado foram fortemente influenciadas pelas disputas políticas da década anterior e que opunham, de um lado, o alvarismo e seus aliados (PSD, UDN, PSP) e, de outro, o PTB e suas principais lideranças (Plínio Coelho e Gilberto Mestrinho). Como vimos, com o golpe de 1964, o governador Plínio Ramos Coelho foi deposto e as principais lideranças trabalhistas do estado tiveram seus mandatos cassados. A extinção dos partidos políticos e a criação das novas legendas representaram mais um golpe sobre a democracia e buscavam enterrar - às vezes literalmente - o legado trabalhista no país.

\section{REFERÊNCIAS}

AMARAL, G. Fábio Lucena: um senador amazônida. In: QUEIRÓS, C. A. B.; UGARTE, A. (org.). Trajetórias Políticas na Amazônia Republicana. Manaus: Valer, 2019. p. 175-194

BRASIL. Ato Institucional n. 1, de 09 de abril de 1964 (A1-1). Disponível em: http://www.planalto.gov.br/ccivil_03/ait/ait-01-64.htm

BRASIL. Presidência da República. Casa Civil. Subchefia para Assuntos Jurídicos. Ato Institucional $n^{\circ} 2$, de 27 de outubro de 1965. Diário Oficial da União. Brasília, 27 out. 1965. Seção 1, p. 11017. Disponível em: http://www.planalto.gov.br/ccivil_03/ait/ait-02-65.htm

BRASIL. Ato Institucional n. 3, de 05 de fevereiro de 1966 (A1-3). Disponível em: http://www.planalto.gov.br/ccivil_03/ait/ait-03-

66.htm\#: :text=ATO $\% 20$ INSTITUCIONAL $\% 20 \mathrm{~N} \% \mathrm{C} 2 \% \mathrm{BA} \% 203 \% 2 \mathrm{C} \% 20 \mathrm{DE}, \mathrm{Estados} \% 20 \mathrm{e} \% 20 \mathrm{~d}$ $\%$ C3\%A1\%20outras $\% 20$ provid $\%$ C3\%AAncias.

BRASIL. Ato Complementar n. 4, de 20 nov. 1965 (AC-4). Disponível em: http://www6.senado.gov.br/legislacao/ListaPublicacoes.action?id=116094

BRASIL. Comissão Nacional da Verdade (CNV). Relatório - Comissão Nacional da Verdade. Recurso eletrônico. Brasília: CNV, 2014.

BATISTELLA, A. O processo de formação da Aliança Renovadora Nacional (ARENA) e do Movimento Democrático Brasileiro (MDB) no Paraná (1965-1966). Saeculum: Revista de História, João Pessoa, v. 25, n. 42., p.191-206, jan.-jun.2020.

CARVALHO, A. Elites politicas durante o regime militar: um estudo sobre os parlamentares da AREN $A$ e do MDB. Tese (Doutorado em Sociologia) - Universidade Federal do Rio de Janeiro, 2008.

FICO, C. Versões e controvérsias sobre 1964 e a ditadura militar. Revista Brasileira de História. São Paulo, v. 24 , n. 47 , p. 29-60, 2004.

GARCIA, E. O poder judiciário na história do Amazonas. Imprenta: Manaus: Tribunal de Justiça do Estado do Amazonas, 2002.

GRINBERG, L. Partido politico on bode expiatório: um estudo sobre a Aliança Renovadora Nacional (Arena), 1965-1979. Rio de Janeiro: Mauad X, 2009. 
KINZO, M. D’A. G. Oposição e autoritarismo: gênese e trajetória do MDB (1966-1979). São Paulo: Vértice, 1988.

MOTTA, R. P. S. A formação do MDB e a influência do quadro partidário anterior. Revista de Sociologia e Política, n. 6-7, p. 201-212, 1996.

QUEIRÓS, C. A. B. "Amazônia em armas": luta e resistência contra a ditadura militar no Amazonas. Labirinto, Porto Velho, Ano xix, v. 31 , n.1, jul-dez 2019a, p. 38-57.

QUEIRÓS, C. A. B. A experiência democrática no Amazonas: a formação do PTB e a consolidação do Trabalhismo (1945/1964). Mundos do Trabalho, Florianópolis, v. 12, p. 1-23, 2020.

QUEIRÓS, C. A. B. O golpe de 1964 no Amazonas e a deposição do governador Plínio Coelho. Antiteses, Londrina, v.11, n. 22, p. 542-562, jan-jul. 2019b.

QUEIRÓS, C. A. B. O Trabalhismo de Plínio Ramos Coelho e o Golpe de 1964 no Amazonas. Mundos do Trabalho, Florianópolis, v. 8, n. 15, p. 49-65, 2016.

SOBREIRA, D. da S. B. Para além do "sim, senhor": a Aliança Renovadora Nacional (ARENA) e a ditadura militar na Paraíba. Dissertação (Mestrado em História) - Universidade Federal da Paraíba, João Pessoa, 2016.

ARTHUR VIRGÍLIO FILHO. Texto e organização de Mário Adolfo. Brasília: Câmara dos Deputados, Edições Câmara, 2011. (Série Perfis Parlamentares, 59). 